\title{
Evaluation of childhood Sluggish Cognitive Tempo among patients with substance use disorder, substance-induced psychosis and childhood ADHD
}

\author{
Ahmet Gul' ${ }^{1 \oplus}$, Hesna Gul²® \\ 'Ufuk University, Faculty of Medicine, Department of Psychiatry, Ankara - Turkey \\ ${ }^{2}$ Gulhane Research and Training Hospital, Department of Child and Adolescent Psychiatry, Ankara - Turkey
}

\begin{abstract}
Objective: Substance use disorders (SUDs) include a pathological pattern of behaviors related with the effects of the drug used and are associated with substance-induced psychosis (SIP). Individuals with lower levels of self-control are particularly predisposed to develop SUDs and SIP. The purpose of this study was to evaluate whether childhood sluggish cognitive tempo (SCT), which is a problem distinct from but related with ADHD, is associated with SUDs and SIP.
\end{abstract}

Method: Fifty-seven SUD patients who had childhood ADHD symptoms and at least one SIP attack were enrolled the study. Patients were evaluated by Brief Psychiatric Rating Scale (BPRS), Wender-Utah Rating Scale (WURS), and SCT Scale.

Results: The rate of childhood SCT comorbidity was $63.8 \%$. The total BPRS and conceptual disorganization, motor retardation, unusual thought content, blunted affect, excitement, and disorientation scores were higher in the childhood SCT group. SCT and WURS scores were positively correlated with BPRS scores but WURS scores were correlated with more psychotic symptoms and the correlations were stronger in WURS than SCT except "conceptual disorganization," "motor retardation." and "blunted affect." Using linear regression analysis, we found that both childhood SCT and WURS scores significantly predicted the BPRS total, motor retardation, unusual thought content, blunted affect and excitement scores. Finally, the results of multivariate stepwise regression analyses indicated that tension and guilt significantly predicted WURS while blunted affect and conceptual disorganization predicted SCT scores.

Conclusion: Approximately, 7 in 10 patients in this group seem to have had childhood SCT. SCT patients showed more proneness to psychotic symptoms when compared with others. In addition, there was a relationship between blunted affect, conceptual disorganization, and SCT.

Keywords: Attention deficit hyperactivity disorder, childhood, sluggish cognitive tempo, substance use disorders, substanceinduced psychosis

\section{INTRODUCTION}

Substance use disorders (SUDs) involve a pathological pattern of behaviors related to the effects of the drug used and are defined as a part of "Substance-Related Disorders" in the DSM-5 (1). SUDs are associated with a substantial burden through impairment in major life roles, including a burden on social networks, increased

How to cite this article: Gul A, Gul H. Evaluation of childhood Sluggish Cognitive Tempo (SCT) among patients with substance use disorder, substance-induced psychosis and childhood ADHD. Dusunen Adam The Journal of Psychiatry and Neurological Sciences 2019;32:142-51.

Correspondence: Hesna Gul, Gulhane Research and Training Hospital, Department of Child and Adolescent Psychiatry, General Dr. Tevfik Saglam Cd. No:1 Etlik - Ankara

Phone: +90 3123042000 E-mail: drhesnagul@gmail.com

Received: October 17, 2018 Revised: January 01, 2019 Accepted: April 03, 2019 
risk for suicidality, neuropsychological deficits, substance-induced psychosis (SIP), and diminished quality of life (2-5). SUDs encompass many classes of substances directly activating the brain reward system, although the pharmacological mechanisms that produce the reward are different (1). Individuals with lower levels of self-control, possibly reflecting impairments of brain inhibitory mechanisms, may be particularly predisposed to develop SUDs and SIP, and one of the most important disorders in this group is attention deficit hyperactivity disorder (ADHD) (1).

ADHD is an early-onset neurobehavioral disorder, affecting $1-20 \%$ of school-age children $(6,7)$ and $4.4 \%$ of adults $(7,8)$. It is highly heritable, persistent across the lifespan (9), and is associated with reduced academic and occupational performance, social rejection, higher probability of unemployment, and elevated interpersonal conflict. Children with ADHD are more likely to develop antisocial personality disorder in adulthood, consequently increasing the likelihood of SUDs, SIP, and incarceration (1,10-12).

Although an increasing body of literature shows an intriguing link between ADHD and SUD, the nature of the relationship remains unclear. One possible explanation is that individuals with ADHD use substances to relieve painful effects or to control their emotions, which can be considered a self-medicating method (13). Supporting this hypothesis, Wilens and Decker (14) found that the use of nicotinic agents for ADHD symptoms improved attention and executive functioning among adolescents and adults both with and without ADHD. In many studies, young adults with ADHD reported that they had initiated and continued their self-medication by nicotinic agents or other substances to attenuate their mood and improve their sleep, and using marijuana calmed their internal restlessness (15-18).

Structural brain abnormalities also suggest a possible biological link between ADHD and SUD. Of these abnormalities, smaller volumes of the frontal cortex, cerebellum and subcortical structures; deficits in anterior cingulate activation and frontosubcortical systems, and variances in the differential development of the frontal/executive/inhibitory and limbic/reward systems in ADHD seem important (19,20). In addition, there are similarities in the dopamine systems and striatal involvement between the two disorders (21). A recent study that compared the striatal dopamine transporter density in three groups ( treatment-naive adolescents with ADHD, treatment-naive adolescents with ADHD and SUD, and healthy controls) revealed that adolescents with ADHD and SUD had a lower striatal density than the others (22). This result supported the self-medication theory. By contrast, findings from other studies indicate that there may be completely different etiological factors including neurocircuitries, genes, and gestational exposures (23).

Another hypothesis about the link between ADHD and SUD considers a developmental progression from childhood ADHD to conduct disorder and eventually SUD and the effect of demoralization and failure on this progression (24). However, this issue have not been examined well.

SUD patients with ADHD are reported to have worse treatment outcomes for both disorders $(25,26)$. More knowledge about the complex patterns of co-occurring mental disorders in SUD and SIP patients with ADHD is important, because different patterns of comorbidity may be partly responsible for lower treatment retention and worse outcomes. One possible co-occurring problem in these patients is sluggish cognitive tempo (SCT).

SCT is characterized by sluggishness, excessive daydreaming, lethargy/apathy, slowed behavior/ thinking, and mental confusion (27-29). For a long time, this symptom set has been closely associated with the inattentive symptoms of ADHD (30-32), but in recent studies, SCT symptoms have been found in populations without $\operatorname{ADHD}(33,34)$ and many studies have demonstrated that SCT has internal and external validity and is distinct from other dimensions of child and adult psychopathology $(33,35-40)$. In addition, a moderately strong relationship has been identified between SCT and internalizing symptoms including depression, anxiety, and emotional dysregulation, which are also linked to SUDs and SIP $(29,32,38,41)$. Another possible link is via functional-structural brain abnormalities. Functional MRI studies suggest a difference between SCT and ADHD-inattention types. In a recent study with adolescents, the authors found significant hypoactivity during general attention preparation in the supplementary motor area (SMA) and in the right superior parietal lobe (SPL) during response preparation in ADHD group compared to controls. They also found that in the ADHD group, greater numbers of SCT symptoms were associated with hypoactivity in the left SPL, whereas greater numbers of inattentive symptoms were associated with greater activity in the SMA. They thought that hypoactivity in the SPL with increasing SCT symptoms may be associated with impaired reorienting or shifting of attention. On the other hand, altered activity in the 
SMA and thalamus with increasing inattention may be associated with a general problem with response preparation, which may also reflect inefficient processing of the response preparation cue (42). In another study with adolescents, both early-onset schizophrenia and cannabis-use disorder patients had a smaller gray matter volume, associated with lower surface area, in the left superior parietal region, compared with healthy controls (43). These studies bring to mind that there may be a common etiological background resulting from functional and/or structural problems in the parietal lobe both in SCT and SUDs.

In this study, our aim was to evaluate the possible relationship of childhood SCT and ADHD symptoms with SUDs and SIP symptoms. As mentioned above, epidemiological studies and brain imaging studies reveal that childhood ADHD is a risk factor for SUDs and SIP. However, childhood SCT, which is closely associated with ADHD, has never before been investigated in this important patient group. Investigation of childhood SCT, which is especially associated with internalizing disorders in SUDs and SIP patients, will be an important contribution to the literature.

Our hypotheses were as follows:

- Childhood SCT rates are higher in SUD and SIP patients with childhood ADHD than in the normal population.

- In this sample, individuals with childhood SCT have more psychotic symptoms than non-SCT ones. In other words, there are differences in current clinical manifestations between SCT and non-SCT patients.

- SCT symptoms could predict some of the psychotic symptoms and there would be differences when compared with ADHD.

\section{METHOD}

\section{Participants and Procedure}

The research protocol was approved by the Research Ethics Board of Ufuk University, School of Medicine. Firstly, all patients who presented to Kahramanmaras Necip Fazil State Hospital, AMATEM outpatient clinics (a specific clinic for SUD patients) between February 2016 and February 2017 were evaluated according to DSM- 5 criteria by the first author, who then asked patients diagnosed with SUDs if they had undergone an SIP attack during their substance use history and whether they had had ADHD symptoms in their childhood. There were 67 patients who met both of these criteria. When the aim and procedure of the study were explained to these patients, 10 persons did not want to participate in the study. Written informed consent was obtained from the remaining participants, and they completed the WURS (Wender-Utah Rating Scale). Then they were evaluated with the Brief Psychiatric Rating Scale (BPRS) and the SCT scale in a semi-structured interview conducted by the first author.

\section{Measures}

Brief Psychiatric Rating Scale (BPRS): The Brief Psychiatric Rating Scale (BPRS) is a widely-used instrument for assessing the positive, negative, and affective symptoms of individuals who have psychotic disorders. It was first published in 1962 by Overall and Gorham (44). It consists of 18 symptom constructs (Somatic Concern, Anxiety, Emotional Withdrawal, Conceptual Disorganization, Guilt Feelings, Tension, Mannerisms and Posturing, Grandiosity, Depressive Mood, Hostility, Suspiciousness, Hallucinatory Behavior, Motor Retardation, Uncooperativeness, Unusual Thought Content, Blunted Affect, Excitement and Disorientation) rated from 0 (not present) to 6 (extremely severe). The validity and reliability of the scale in Turkish was determined in 1989 (45). It was administered to the patients by the first author who is an adult psychiatrist.

Sluggish Cognitive Tempo Scale: To assess the sluggish cognitive tempo (SCT), we used the Turkish translation of the adult version of Barkley's SCT Rating Scale. Originally, this is a self-report scale consisting of 9 symptoms chosen from the symptom sets used in prior studies of SCT in adults, including the following items: "Prone to daydreaming when I should be

Table 1: Sociodemographic features and types of substances patients use

\begin{tabular}{lccc} 
Demographics & Min-Max & Mean & SD \\
\hline Age & $17-56$ & 29.35 & 8.74 \\
Education (years) & $3-15$ & 8.29 & 2.41 \\
Number of substances used & $2-8$ & 4.85 & 1.80 \\
Types of substance & $\mathbf{n}$ & \% & \\
\cline { 2 - 3 }$\quad$ Cigarette & 53 & 93.0 & \\
Alcohol & 45 & 78.9 & \\
Marijuana & 46 & 80.7 & \\
Cocaine & 8 & 14.0 & \\
Heroin & 44 & 77.2 & \\
$\quad$ Ecstasy & 29 & 50.9 & \\
Bonsai & 7 & 12.3 & \\
$\quad$ Volatile solvents & 9 & 15.8 & \\
\hline
\end{tabular}


concentrating"; "have trouble staying alert or awake in boring situations"; "easily confused"; "easily bored"; "spacey or in a fog"; "lethargic, more tired than others"; "underactive or have less energy than others"; "slow moving"; "I don't seem to process information as quickly or as accurately as others." These symptoms have been proposed to form a factor or dimension distinct from the DSM symptoms of ADHD (28). In our study, we administered the tool to the patients in a semi-structured way and investigated the childhood SCT symptoms. The score used here was the number of SCT symptoms rated "often" or "very often" regarding their childhood. If a patient scored 5 or more times "often" to "very often," we included him in the SCT group. Unfortunately, a validity and reliability study of the scale has not yet been done. For this reason, we assessed the internal consistency in our sample and found that Cronbach's alpha was 0.92 for 9 items. In comparison with the internal consistency (Cronbach's alpha) of the items for Barkley's sample, which was 0.898 (28), the scale was found to be highly reliable in our sample, too.

Wender-Utah Rating Scale (WURS): The WenderUtah Rating Scale (WURS) is a self-report scale that was developed to investigate childhood symptoms of ADHD retrospectively as an aid for the diagnosis of ADHD in adults (46). It is based upon the Utah criteria, which were developed to diagnose ADHD in adults. First, a 61-item five-point Likert-type self-assessment scale inquiring about ADHD symptoms in childhood was developed. The 25 items of the scale showing the greatest difference between normal comparison subjects and patients with ADHD are selected and scored. The total WURS score is the sum of these 25 items, ranging from $0-100$. The validity and reliability study of the Turkish version was conducted by Oncu et al. (47). After examining sensitivity and specificity of the WURS for various cut-off scores, a score of 36 was determined as cut-off point (47).

\section{Statistical Analysis}

Statistical analysis was performed using SPSS 22.0. Demographic information was analyzed through descriptive statistics. Chi-square test was used for categorical variables and the Kolmogorov-Smirnov test was used to test for normality. The scores were compared between the SCT and non-SCT groups with Student's t-test or Mann-Whitney U test. As mentioned earlier, if a patient scored 5 or more times "often" to "very often" on the SCT scale, we categorized him in SCT group.
Correlation analysis was performed with Pearson or Spearman correlation tests. Linear regression (Enter model) was used to determine if SCT or WURS scale scores predicted BPRS subscales. Finally, stepwise regression analysis was performed for SCT total and WURS total scores by using age, education time and the BPRS subscale scores that had a significant $p$ value in linear regression analyses. A p value $<0.05$ was accepted as statistically significant.

\section{RESULTS}

The entire sample consisted of male patients, aged between 17 and 56 years $(\mathrm{M}=29.35, \mathrm{SD}=8.74)$. Their period of education was between 3 and 15 years $(\mathrm{M}=8.29, \mathrm{SD}=2.41)$. All of them used more than one substance $(\mathrm{M}=4.85, \mathrm{SD}=1.80)$, the most commonly used ones being tobacco, alcohol, marijuana, heroin, and ecstasy (Table 1). Their substance use period varied from 1 to 11 years $(\mathrm{M}=2.5, \mathrm{SD}=2.4)$. All participants had been diagnosed with SUDs and were undergoing medical treatment.

The rate of having childhood sluggish cognitive tempo (SCT) was $63.8 \%(n=37)$ in our sample. There were no significant differences between patients with SCT and without SCT according to sociodemographic and substance use features including age, period of education, and the number of substances used (Table 2).

The mean total BPRS scores and conceptual disorganization, motor retardation, unusual thought content, blunted affect, excitement, and disorientation scores were significantly higher among patients with SCT than in patients without SCT $(p=0.009 ; p=0.007$; $\mathrm{p}=0.006 ; \mathrm{p}=0.001 ; \mathrm{p}=0.01 ; \mathrm{p}=0.01 ; \mathrm{p}=0.03$ respectively) while other subitems were not significantly different ( $p>0.05$ ) between groups (Table 2 ).

When we assessed the correlations between SCTWURS total and BPRS total, we found that SCT and WURS scores were positively correlated with total BPRS scores and the correlations were moderately strong ( $r=0.53, r=0.69$, respectively). The relationship between BPRS and WURS was stronger than between BPRS and SCT (Table 3). In addition, WURS scores were correlated more to psychotic symptom scores than SCT (WURS scores were positively and significantly correlated with 16 out of 18 BPRS subitems while SCT scores were correlated only with 13), and the correlations were stronger in WURS except for "conceptual disorganization," "motor retardation," and "blunted affect" (Table 3). 
Table 2: Comparisons between SCT and non-SCT patients

\begin{tabular}{|c|c|c|c|c|c|c|c|}
\hline & \multicolumn{2}{|c|}{ Non-SCT $(n=20)$} & \multicolumn{2}{|c|}{ SCT $(n=37)$} & \multirow[b]{2}{*}{$\mathbf{t}$} & \multirow[b]{2}{*}{ df } & \multirow[b]{2}{*}{$\mathbf{p}$} \\
\hline & Mean & SD & Mean & SD & & & \\
\hline Age & 29.70 & 8.80 & 28.30 & 9.48 & -0.55 & 55 & 0.579 \\
\hline Education & 8.43 & 2.70 & 8.05 & 1.79 & 0.56 & 55 & 0.573 \\
\hline Number of substances & 4.89 & 1.86 & 4.80 & 1.73 & -0.018 & 55 & 0.857 \\
\hline Wender-Utah Rating Scale & 57.20 & 20.57 & 69.67 & 10.57 & -3.034 & 55 & 0.004 \\
\hline BPRS total & 51.15 & 21.49 & 63.56 & 13.16 & -2.707 & 55 & 0.009 \\
\hline Somatic concern & 3.05 & 1.66 & 3.21 & 1.84 & -0.336 & 55 & 0.738 \\
\hline Anxiety & 3.25 & 1.29 & 3.70 & 1.46 & -1.156 & 55 & 0.253 \\
\hline Emotional withdrawal & 3.20 & 1.60 & 3.83 & 1.21 & -1.686 & 55 & 0.098 \\
\hline Conceptual disorganization & 2.95 & 1.23 & 3.86 & 1.13 & -2.818 & 55 & 0.007 \\
\hline Guilt feelings & 3.95 & 20.01 & 4.62 & 0.89 & -1.419 & 55 & 0.169 \\
\hline Tension & 4.00 & 1.55 & 4.59 & 1.25 & -1.566 & 55 & 0.123 \\
\hline Mannerisms and posturing & 3.20 & 1.79 & 3.27 & 1.53 & -0.155 & 55 & 0.877 \\
\hline Grandiosity & 1.90 & 1.65 & 1.64 & 1.79 & -0.518 & 55 & 0.607 \\
\hline Depressive mood & 3.45 & 1.66 & 4.21 & 1.29 & -1.924 & 55 & 0.060 \\
\hline Hostility & 2.35 & 2.08 & 3.08 & 1.75 & -1.405 & 55 & 0.166 \\
\hline Suspiciousness & 2.85 & 1.92 & 3.48 & 1.81 & -1.235 & 55 & 0.222 \\
\hline Hallucinatory behavior & 1.85 & 1.89 & 2.72 & 2.02 & -1.600 & 55 & 0.115 \\
\hline Motor retardation & 2.35 & 1.78 & 3.70 & 1.68 & -2.837 & 55 & 0.006 \\
\hline Uncooperativeness & 2.75 & 1.74 & 3.16 & 1.77 & -0.843 & 55 & 0.403 \\
\hline Unusual thought content & 2.15 & 1.63 & 3.56 & 1.46 & -3.353 & 55 & 0.001 \\
\hline Blunted affect & 3.05 & 1.53 & 4.05 & 0.91 & -2.676 & 55 & 0.013 \\
\hline Excitement & 2.60 & 1.60 & 3.62 & 1.27 & -2.633 & 55 & 0.011 \\
\hline Disorientation & 2.25 & 1.58 & 3.18 & 1.56 & -2.157 & 55 & 0.035 \\
\hline
\end{tabular}

SCT: Sluggish cognitive tempo

When we used linear regression analysis, we found that both childhood SCT and WURS scores significantly predicted the BPRS total, motor retardation, unusual thought content, blunted affect, and excitement scores. In addition, SCT scores predicted conceptual disorganization, while WURS scores predicted emotional withdrawal, guilt feelings, tension, mannerism and posturing, grandiosity, depressive mood, hostility, suspiciousness, and hallucinatory behavior (Table 4). Finally, the results of multivariate stepwise regression analyses indicated that three predictors explained $70.9 \%$ of the variance for WURS total scores $\left(\mathrm{R}^{2}=0.50, \mathrm{~F}=17.83, \mathrm{p}<0.001\right)$. It was found that tension significantly predicted WURS scores $(\beta=0.32, p=0.008)$, as did guilt $(\beta=0.29, p=0.017)$, and unusual thought content $(\beta=0.26, p=0.019)$. On the other hand, regression analyses indicated that two predictors explained $63.6 \%$ of the variance for SCT total scores $\left(R^{2}=0.40, F=18.33, p<0.001\right)$. It was found that blunted affect significantly predicted SCT scores $(\beta=0.43, p<0.001)$, as did conceptual disorganization $(\beta=0.38, p=0.012)$ (Table.5).

\section{DISCUSSION}

In this study, for the first time we evaluated childhood SCT symptoms among SUD patients and examined the relationship between childhood SCT, ADHD, and BPRS scores. Initially, we had 4 hypotheses. The first one was: "SCT rates are higher in SUD and SIP patients with childhood ADHD than in the normal population." We found that the ratio of SCT comorbidity was $63.8 \%$ in our sample. To date, SCT ratios have been shown to be $5.8-23 \%$ among adult- young adult samples $(33,41)$. Unfortunately, we did not find any evidence about childhood SCT ratios in adults. Our results demonstrated that the childhood SCT ratio was 3 to 10 times higher in SUDs patients with childhood ADHD compared with current SCT ratios in normal adult populations. In addition, our results demonstrated that 


\begin{tabular}{|c|c|c|c|}
\hline & $\begin{array}{l}\text { SCT } \\
\text { Scale }\end{array}$ & $\begin{array}{l}\text { BPRS total } \\
\text { score }\end{array}$ & $\begin{array}{l}\text { WURS } \\
\text { total score }\end{array}$ \\
\hline SCT scale & 1 & $0.53^{* *}$ & $0.46^{* *}$ \\
\hline WURS total score & $0.46^{* *}$ & $0.69^{* *}$ & 1 \\
\hline BPRS total score & $0.53^{* *}$ & 1 & $0.69 * *$ \\
\hline Somatic concern & 0.18 & $0.42^{* *}$ & 0.24 \\
\hline Anxiety & $0.29 *$ & $0.52^{* *}$ & $0.29 *$ \\
\hline $\begin{array}{l}\text { Emotional } \\
\text { withdrawal }\end{array}$ & $0.30^{*}$ & $0.55^{* *}$ & $0.39 * *$ \\
\hline $\begin{array}{l}\text { Conceptual } \\
\text { disorganization }\end{array}$ & $0.50^{* *}$ & $0.58^{* *}$ & $0.37^{* *}$ \\
\hline Guilt feelings & $0.34^{* *}$ & $0.67^{* *}$ & $0.57^{* *}$ \\
\hline Tension & $0.27^{*}$ & $0.65^{* *}$ & $0.59^{* *}$ \\
\hline $\begin{array}{l}\text { Mannerisms and } \\
\text { posturing }\end{array}$ & 0.14 & $0.59 * *$ & $0.47^{* *}$ \\
\hline Grandiosity & 0.007 & $0.40^{* *}$ & $0.28^{*}$ \\
\hline Depressive mood & $0.39^{* *}$ & $0.73^{* *}$ & $0.45^{* *}$ \\
\hline Hostility & $0.29^{* *}$ & $0.69^{* *}$ & $0.34^{* *}$ \\
\hline Suspiciousness & 0.25 & $0.62^{* * *}$ & $0.45^{* *}$ \\
\hline $\begin{array}{l}\text { Hallucinatory } \\
\text { behavior }\end{array}$ & $0.33^{*}$ & $0.72^{* * *}$ & $0.34^{* *}$ \\
\hline Motor retardation & $0.55^{* *}$ & $0.65^{* *}$ & $0.45^{* *}$ \\
\hline Uncooperativeness & 0.20 & $0.38^{* *}$ & 0.13 \\
\hline $\begin{array}{l}\text { Unusual thought } \\
\text { content }\end{array}$ & $0.49^{* *}$ & $0.72^{* *}$ & $0.52^{* *}$ \\
\hline Blunted affect & $0.57^{* *}$ & $0.71^{* *}$ & $0.50^{* *}$ \\
\hline Excitement & $0.44^{* *}$ & $0.61^{* *}$ & $0.49^{* *}$ \\
\hline Disorientation & $0.40^{* *}$ & $0.63^{* *}$ & $0.42^{* *}$ \\
\hline
\end{tabular}

${ }^{*} \mathrm{p}<0.05,{ }^{* *} \mathrm{p}<0.001$ level (Pearson Correlations)

SCT: Sluggish cognitive tempo, WURS: Wender-Utah Rating Scale, BPRS: Brief Psychiatric Rating Scale

the ratio of childhood SCT-ADHD comorbidity is higher in our sample than the previous studies among children, adolescents, and adults (27,32-34).

Until now, many studies have assessed the prospective risk of developing SUD following childhood mental health disorders including attention deficit hyperactivity disorder (ADHD), oppositional defiant disorder/conduct disorder (ODD/CD), anxiety disorder, and depression. A recent meta-analysis showed a significantly increased risk for addiction in childhood ADHD and depression but not anxiety disorders (48). It is well known that there is a notable overlap between ADHD-predominantly of the inattentive type-and SCT symptoms (49). As mentioned above, our results revealed that childhood SCT and ADHD comorbidity is fairly high among SUD patients with SIP. Studies also showed that SCT symptoms are correlated with internalizing symptoms, burnout, sleep problems, social withdrawal, depression, and anxiety in different age and sociocultural groups (50-56). Although it is not possible to evaluate causality in a cross-sectional study like the present one, it can be speculated that childhood SCT-ADHD comorbidity might be associated with SUDs in adulthood and the increased risk could be derived from the relationship of internalizing disorders and SCT.

Childhood/adulthood ADHD is common among SIP patients, too $(12,57,58)$. However, to date no study has evaluated the relationship between substanceinduced psychosis and SCT. One of our hypotheses was: "Patients with childhood SCT have more psychotic symptoms than non-SCT ones. In other words, there are differences in current clinical manifestations between SCT and non-SCT patients." Our results demonstrate that total BPRS, conceptual disorganization, motor retardation, unusual thought content, blunted affect, excitement, and disorientation symptom scores were higher in the SCT group. These results showed that childhood SCT symptoms are related both with negative and positive psychotic symptoms and should be addressed in larger samples in the future.

Finally, our fourth hypothesis was: "SCT symptoms could predict some of the psychotic symptoms and there would be differences when compared with ADHD." Correlation and linear regression analyses revealed that the relationship between conceptual disorganization, motor retardation, blunted affect symptoms and SCT were stronger than with ADHD symptoms, and SCT scores predicted conceptual disorganization, while WURS scores predicted emotional withdrawal, guilt feelings, tension, mannerism and posturing, grandiosity, depressive mood, hostility, suspiciousness, and hallucinatory behavior. On the other hand, the results of the multivariate stepwise regression analyses indicated that tension and guilt scores significantly predicted WURS scores, while blunted affect and conceptual disorganization predicted SCT scores. These results are consistent with the early internal and external validity studies of SCT in adults $(33,59,60)$, and it should be kept in mind that childhood SCT could be another important risk factor for SUDs and SIP.

Our study has several limitations: The small sample size does not allow generalizing our findings to all SUD patients with SIP. We could not find a tool to measure childhood SCT; instead, we applied the adult SCT Scale in a retrospective way. Therefore, recall biases should 
Table 4: Predictors of SCT Total and WURS total in linear regression model

\begin{tabular}{|c|c|c|c|c|c|c|}
\hline & \multicolumn{2}{|c|}{ SCT total score } & \multicolumn{2}{|c|}{ WURS total score } & \multicolumn{2}{|c|}{ ANOVA statistics } \\
\hline & B & $\mathbf{p}$ & B & $\mathbf{p}$ & $F(2.54)$ & $\mathbf{p}$ \\
\hline BPRS total & 0.27 & 0.01 & 0.56 & $<0.001$ & 31.85 & $<0.001$ \\
\hline Somatic concern & 0.08 & 0.56 & 0.20 & 0.17 & 1.93 & 0.15 \\
\hline Anxiety & 0.20 & 0.17 & 0.20 & 0.15 & 3.70 & 0.03 \\
\hline Emotional withdrawal & 0.15 & 0.26 & 0.32 & 0.02 & 5.79 & $<0.001$ \\
\hline Conceptual disorganization & 0.41 & 0.002 & 0.18 & 0.17 & 10.47 & $<0.001$ \\
\hline Guilt feelings & 0.10 & 0.42 & 0.53 & $<0.001$ & 14.02 & $<0.001$ \\
\hline Tension & -0.001 & 0.99 & 0.59 & $<0.001$ & 14.68 & $<0.001$ \\
\hline Mannerisms and posturing & -0.09 & 0.48 & 0.52 & $<0.001$ & 8.37 & $<0.001$ \\
\hline Grandiosity & -0.16 & 0.26 & 0.36 & 0.01 & 3.13 & 0.05 \\
\hline Depressive mood & 0.22 & 0.09 & 0.34 & 0.01 & 8.92 & $<0.001$ \\
\hline Hostility & 0.03 & 0.80 & 0.56 & $<0.001$ & 13.55 & $<0.001$ \\
\hline Suspiciousness & 0.04 & 0.71 & 0.43 & 0.002 & 7.25 & 0.002 \\
\hline Hallucinatory behavior & 0.22 & 0.12 & 0.24 & 0.009 & 4.98 & 0.01 \\
\hline Motor retardation & 0.43 & 0.001 & 0.25 & 0.042 & 14.92 & $<0.001$ \\
\hline Uncooperativeness & 0.17 & 0.24 & 0.05 & 0.71 & 0.12 & 0.30 \\
\hline Unusual thought content & 0.32 & 0.01 & 0.37 & 0.003 & 15.21 & $<0.001$ \\
\hline Blunted affect & 0.43 & 0.001 & 0.30 & 0.01 & 18.17 & $<0.001$ \\
\hline Excitement & 0.27 & 0.03 & 0.36 & 0.006 & 11.68 & $<0.001$ \\
\hline Disorientation & 0.26 & 0.059 & 0.30 & 0.02 & 8.33 & 0.001 \\
\hline
\end{tabular}

SCT: Sluggish Cognitive Tempo, WURS: Wender-Utah Rating Scale, BPRS: Brief Psychiatric Rating Scale

Table 5: Results of stepwise regression for dependent variables SCT Total and WURS total

\begin{tabular}{|c|c|c|c|c|c|c|}
\hline Dependent variable: SCT total & $\mathbf{R}^{2}$ & F change & $\boldsymbol{\beta}$ & ANOVA statistics & t (in the model) & $\mathbf{p}$ \\
\hline Model 1 & 0.32 & 26.97 & & $F=26.97, p<0.001$ & & \\
\hline Blunted affect & & & 0.57 & & 5.19 & $<0.001$ \\
\hline Model 2 & 0.40 & 6.83 & & $F=18.33, p<0.001$ & & \\
\hline Blunted affect & & & 0.43 & & 3.96 & $<0.001$ \\
\hline Conceptual disorganization & & & 0.38 & & 2.01 & 0.012 \\
\hline Dependent variable: WURS total & $\mathbf{R}^{2}$ & F change & $\boldsymbol{\beta}$ & ANOVA Statistics & t (in the model) & $\mathbf{p}$ \\
\hline Model 1 & 0.35 & 29.90 & & $F=29.90, p<0.001$ & & \\
\hline Tension & & & 0.59 & & 5.46 & $<0.001$ \\
\hline Model 2 & 0.44 & 9.30 & & $F=21.86, p<0.001$ & & \\
\hline Tension & & & 0.39 & & 3.32 & 0.002 \\
\hline Guilt & & & 0.36 & & 3.05 & 0.004 \\
\hline Model 3 & 0.50 & 5.84 & & $F=17.83, p<0.001$ & & \\
\hline Tension & & & 0.32 & & 2.73 & 0.008 \\
\hline Guilt & & & 0.29 & & 2.45 & 0.017 \\
\hline Unusual thought content & & & 0.26 & & 2.41 & 0.019 \\
\hline
\end{tabular}

SCT: Sluggish Cognitive Tempo, WURS: Wender-Utah Rating Scale, BPRS: Brief Psychiatric Rating Scale

be mentioned when evaluating our results. In addition, been done, and finally, there was no control group with although we assessed internal consistency ourselves, only childhood ADHD (without SIP) to compare the validity and reliability studies for the scale have not yet SCT rates. 
In conclusion, this study was the first investigating the ratio of childhood sluggish cognitive tempo in SUD patients and the relationship between psychotic symptoms and SCT scores compared with ADHD scores. Approximately 7 in 10 SUD patients with childhood ADHD seem to have childhood SCT. In this sample, patients with sluggish cognitive tempo were more prone to psychotic symptoms compared with non-SCT ones. Further prospective studies should be performed to reveal the effect of childhood SCT on SUDs and SIP to develop preventive methods.

\begin{tabular}{|c|c|c|}
\hline \multicolumn{2}{|c|}{ Contribution Categories } & Author Initials \\
\hline \multirow{3}{*}{ Category 1} & Concept/Design & A.G., H.G. \\
\hline & Data acquisition & A.G., H.G. \\
\hline & Data analysis/Interpretation & A.G., H.G. \\
\hline \multirow{2}{*}{ Category 2} & Drafting manuscript & A.G., H.G. \\
\hline & Critical revision of manuscript & A.G., H.G. \\
\hline Category 3 & Final approval and accountability & A.G., H.G. \\
\hline \multirow{2}{*}{ Other } & Technical or material support & A.G., H.G. \\
\hline & Supervision & N/A \\
\hline
\end{tabular}

Ethics Committee Approval: The research protocol was approved by the Research Ethics Board of Ufuk University, School of Medicine.

Informed Consent: Written informed consent was obtained from the patients.

Peer-review: Externally peer-reviewed.

Conflict of Interest: The authors declared no conflicts of interest.

Financial Disclosure: The authors declared no financial support.

\section{REFERENCES}

1. American Psychiatric Association. Diagnostic and Statistical Manual of Mental Disorders Fifth ed. (DSM-5). Washington DC: American Psychiatric Publ., 2013.

2. O’Brien CP, Charney DS, Lewis L, Cornish JW, Post RM, Woody GE, Zubieta JK, Anthony JC, Blaine JD, Bowden CL, Calabrese JR, Carroll K, Kosten T, Rounsaville B, Childress AR, Oslin DW, Pettinati HM, Davis MA, Demartino R, Drake RE, Fleming MF, Fricks L, Glassman AH, Levin FR, Nunes EV, Johnson RL, Jordan C, Kessler RC, Laden SK, Regier DA, Renner JA Jr, Ries RK, Sklar-Blake T, Weisner C. Priority actions to improve the care of persons with co-occurring substance abuse and other mental disorders: a call to action. Biol Psychiatry 2004; 56:703713.

3. Swendsen JD, Merikangas KR. The comorbidity of depression and substance use disorders. Clin Psychol Rev 2000; 20:173-189.

4. Degenhardt L, Hall W. Extent of illicit drug use and dependence, and their contribution to the global burden of disease. Lancet 2012; 379:55-70.

5. Yuodelis-Flores C, Ries RK. Addiction and suicide: a review. Am J Addict 2015; 24:98-104.
6. Polanczyk G, De Lima MS, Horta BL, Biederman J, Rohde LA. The worldwide prevalence of ADHD: a systematic review and metaregression analysis. Am J Psychiatry 2007; 164: 942-948.

7. Kessler RC, Adler L, Barkley R, Biederman J, Conners CK, Demler O, Faraone SV, Greenhill LL, Howes MJ, Secnik K, Spencer T, Ustun TB, Walters EE, Zaslavsky AM. The prevalence and correlates of adult ADHD in the United States: results from the National Comorbidity Survey Replication. Am J Psychiatry 2006; 163:716-723.

8. Willcutt EG. The prevalence of DSM-IV attention-deficit/ hyperactivity disorder: a meta-analytic review. Neurotherapeutics 2012; 9:490-499.

9. Bidwell LC, Willcutt EG, McQueen MB, DeFries JC, Olson RK, Smith SD, Pennington BF. A family based association study of DRD4, DAT1, and 5HTT and continuous traits of attentiondeficit hyperactivity disorder. Behav Genetics 2011; 41:165-174.

10. van Emmerik-van Oortmerssen K, van de Glind G, van den Brink W, Smit F, Crunelle CL, Swets M, Schoevers RA. Prevalence of attention-deficit hyperactivity disorder in substance use disorder patients: a meta-analysis and meta-regression analysis. Drug Alcohol Depend 2012; 122:11-19.

11. Van de Glind G, Konstenius M, Koeter MW, van Emmerik-van Oortmerssen K, Carpentier P-J, Kaye S, Degenhardt L, Skutle A, Franck J, Bu ET, Moggi F, Dom G, Verspreet S, Demetrovics Z, Kapitany-Foveny M, Fatseas M, Auriacombe M, Schillinger A, Moller M, Johnson B, Faraone SV, Ramos-Quiroga JA, Casas M, Allsop S, Carruthers S, Schoevers RA, Wallhed S, Barta C, Alleman P; IASP Research Group, Levin FR, van den Brink W. Variability in the prevalence of adult ADHD in treatment seeking substance use disorder patients: results from an international multi-center study exploring DSM-IV and DSM-5 criteria. Drug Alcohol Depend 2014; 134:158-166.

12. Dalteg A, Zandelin A, Tuninger E, Levander S. Psychosis in adulthood is associated with high rates of ADHD and CD problems during childhood. Nord J Psychiatry 2014; 68:560-566.

13. Khantzian EJ. The self-medication hypothesis of substance use disorders: a reconsideration and recent applications. Harv Rev Psychiatry 1997; 4:231-244.

14. Wilens TE, Decker MW. Neuronal nicotinic receptor agonists for the treatment of attention-deficit/hyperactivity disorder: focus on cognition. Biochem Pharmacol 2007; 74:1212-1223.

15. Wilens TE. Attention deficit hyperactivity disorder and substance use disorders. Am J Psychiatry 2006; 163:2059-2063.

16. Wilens TE, Fusillo S. When ADHD and substance use disorders intersect: relationship and treatment implications. Curr Psychiatry Rep 2007; 9:408-414.

17. Kaminer Y, Connor DF, Curry JF. Treatment of comorbid adolescent cannabis use and major depressive disorder. Psychiatry (Edgmont) 2008; 5:34-39.

18. Kaminer Y. Youth Substance Abuse and Co-occurring Disorders. Arlington VA: Am Psychiatr Pub, 2015.

19. Wilens TE, Spencer TJ. Understanding attention-deficit/ hyperactivity disorder from childhood to adulthood. Postgrad Med 2010; 122:97-109. 
20. Casey B, Jones RM. Neurobiology of the adolescent brain and behavior: implications for substance use disorders. J Am Acad Child Adolesc Psychiatry 2010; 49:1189-1201.

21. Frodl T. Comorbidity of ADHD and substance use disorder (SUD): a neuroimaging perspective. J Atten Disord 2010; 14:109120.

22. Silva Jr N, Szobot CM, Shih MC, Hoexter MQ, Anselmi CE, Pechansky F, Bressan RA, Rohde LA. Searching for a neurobiological basis for self-medication theory in ADHD comorbid with substance use disorders: an in vivo study of dopamine transporters using $(99 \mathrm{~m})$ Tc-TRODAT-1 SPECT. Clin Nucl Med 2014; 39:e129-e134.

23. Whelan R, Conrod PJ, Poline J-B, Lourdusamy A, Banaschewski T, Barker GJ, Bellgrove MA, Buchel C, Byrne M, Cummins TD, Fauth-Buhler M, Flor H, Gallinat J, Heinz A, Ittermann B, Mann K, Martinot JL, Lalor EC, Lathrop M, Loth E, Nees F, Paus T, Rietschel M, Smolka MN, Spanagel R, Stephens DN, Struve M, Thyreau B, Vollstaedt-Klein S, Robbins TW, Schumann G, Garavan H; IMAGEN Consortium. Adolescent impulsivity phenotypes characterized by distinct brain networks. Nat Neurosci 2012; 15:920-925.

24. Mannuzza S, Klein RG, Konig PH, Giampino TL. Hyperactive boys almost grown up: IV. Criminality and its relationship to psychiatric status. Arch Gen Psychiatry 1989; 46:1073-1079.

25. Arias AJ, Gelernter J, Chan G, Weiss RD, Brady KT, Farrer L, Kranzler HR. Correlates of co-occurring ADHD in drugdependent subjects: prevalence and features of substance dependence and psychiatric disorders. Addict Behav 2008; 33:1199-1207.

26. Castells X, Ramos-Quiroga JA, Rigau D, Bosch R, Nogueira M, Vidal X, Casas M. Efficacy of methylphenidate for adults with attention-deficit hyperactivity disorder. CNS Drugs 2011; 25:157-169.

27. Penny AM, Waschbusch DA, Klein RM, Corkum P, Eskes G. Developing a measure of sluggish cognitive tempo for children: Content validity, factor structure, and reliability. Psychol Assess 2009; 21:380-389.

28. Barkley RA. Barkley Adult ADHD Rating Scale-IV (BAARS-IV). New York: Guilford Press, 2011.

29. Barkley RA. Sluggish cognitive tempo (concentration deficit disorder?): current status, future directions, and a plea to change the name. J Abnorm Child Psychol 2014; 42:117-125.

30. Carlson CL, Mann M. Sluggish cognitive tempo predicts a different pattern of impairment in the attention deficit hyperactivity disorder, predominantly inattentive type. J Clin Child Adolesc Psychol 2002; 31:123-129.

31. Hartman CA, Willcutt EG, Rhee SH, Pennington BF. The relation between sluggish cognitive tempo and DSM-IV ADHD. J Abnorm Child Psychol 2004; 32:491-503.

32. Garner AA, Marceaux JC, Mrug S, Patterson C, Hodgens B. Dimensions and correlates of attention deficit/hyperactivity disorder and sluggish cognitive tempo. J Abnorm Child Psychol 2010; 38:1097-1107.
33. Barkley RA. Distinguishing sluggish cognitive tempo from attention-deficit/hyperactivity disorder in adults. J Abnorm Child Psychol 2012; 121:978-990.

34. Barkley RA. Distinguishing sluggish cognitive tempo from ADHD in children and adolescents: executive functioning, impairment, and comorbidity. J Clin Child Adolescent Psychol 2013; 42:161-173.

35. Becker SP, Luebbe AM, Fite PJ, Stoppelbein L, Greening L. Sluggish cognitive tempo in psychiatrically hospitalized children: Factor structure and relations to internalizing symptoms, social problems, and observed behavioral dysregulation. J Abnorm Child Psychol 2014; 42:49-62.

36. Bernad MdM, Servera M, Grases G, Collado S, Burns GL. A cross-sectional and longitudinal investigation of the external correlates of sluggish cognitive tempo and ADHD-inattention symptoms dimensions. J Abnorm Child Psychol 2014; 42:12251236.

37. Burns GL, Servera M, Bernad MdM, Carrillo JM, Cardo E. Distinctions between sluggish cognitive tempo, ADHD-IN, and depression symptom dimensions in Spanish first-grade children. J Clin Child Adolesc Psychol 2013; 42:796-808.

38. Garner AA, Mrug S, Hodgens B, Patterson C. Do symptoms of sluggish cognitive tempo in children with ADHD symptoms represent comorbid internalizing difficulties? J Atten Disord 2013; 17:510-518.

39. Becker SP, Fite PJ, Garner AA, Greening L, Stoppelbein L, Luebbe AM. Reward and punishment sensitivity are differentially associated with ADHD and sluggish cognitive tempo symptoms in children. J Res Pers 2013; 47:719-727.

40. Lee S, Burns GL, Snell J, McBurnett K. Validity of the sluggish cognitive tempo symptom dimension in children: sluggish cognitive tempo and ADHD-inattention as distinct symptom dimensions. J Abnorm Child Psychol 2014; 42:7-19.

41. Flannery AJ, Becker SP, Luebbe AM. Does emotion dysregulation mediate the association between sluggish cognitive tempo and college students' social impairment? J Atten Disord 2016; 20:802812.

42. Fassbender C, Krafft CE, Schweitzer JB. Differentiating SCT and inattentive symptoms in ADHD using fMRI measures of cognitive control. Neuroimage Clin 2015; 8:390-397.

43. Kumra S, Robinson P, Tambyraja R, Jensen D, Schimunek C, Houri A, Reis T, Lim K. Parietal lobe volume deficits in adolescents with schizophrenia and adolescents with cannabis use disorders. J Am Acad Child Adolesc Psychiatry 2012; 51:171-180.

44. Overall JE, Gorham DR. The brief psychiatric rating scale. Psychol Rep 1962; 10:799-812.

45. Soykan C. Institutional differences and case typicality as related to diagnosis system severity, prognosis and treatment. Postgraduate Thesis, Middle Eastern Technical University, Ankara. 1989. (Turkish)

46. Ward MF, Wender PH, Reimherr FW. The Wender Utah Rating Scale: an aid in the retrospective diagnosis of childhood attention deficit hyperactivity disorder. Am J Psychiatry 1993; 150:885890. 
47. Oncu B, Olmez S, Senturk V. Validity and reliability of the Turkish version of the Wender Utah Rating Scale for attentiondeficit/hyperactivity disorder in adults. Turk Psikiyatri Derg 2005; 16:252-259 (Turkish)

48. Groenman AP, Janssen TW, Oosterlaan J. Childhood psychiatric disorders as risk factor for subsequent substance abuse: a metaanalysis. J Am Acad Child Adolesc Psychiatry 2017; 56:556-569.

49. Saxbe C, Barkley RA. The second attention disorder? Sluggish cognitive tempo vs. attention-deficit/hyperactivity disorder: update for clinicians. J Psychiatric Prac 2014; 20:38-49.

50. Rondon AT, Hilton DC, Jarrett MA, Ollendick TH. Sleep, internalizing problems, and social withdrawal: unique associations in clinic-referred youth with elevated sluggish cognitive tempo symptoms. J Atten Disord 2018:1087054718756197 [Epub ahead of print].

51. Smith ZR, Langberg JM. Predicting academic impairment and internalizing psychopathology using a multidimensional framework of Sluggish Cognitive Tempo with parent-and adolescent reports. Eur Child Adolesc Psychiatry 2017; 26:11411150 .

52. Becker SP, Garner AA, Tamm L, Antonini TN, Epstein JN. Honing in on the social difficulties associated with sluggish cognitive tempo in children: withdrawal, peer ignoring, and low engagement. J Clin Child Adolesc Psychol 2019; 48:228-237.

53. Gul A, Gul H, Ozkal UC, Kincir Z, Gultekin G, Emul HM. The relationship between sluggish cognitive tempo and burnout symptoms in psychiatrists with different therapeutic approaches. Psychiatry Res 2017; 252:284-288.
54. Jacobson LA, Geist M, Mahone EM. Sluggish cognitive tempo, processing speed, and internalizing symptoms: the moderating effect of age. J Abnorm Child Psychol 2018; 46:127-135.

55. Leikauf JE, Solanto MV. Sluggish cognitive tempo, internalizing symptoms, and executive function in adults with ADHD. J Atten Disord 2017; 21:701-711.

56. Koriakin TA, Mahone EM, Jacobson LA. Sleep difficulties are associated with parent report of sluggish cognitive tempo. J Dev Behav Pediatr 2015; 36:717-723.

57. Marwaha S, Thompson A, Bebbington P, Singh SP, Freeman D, Winsper C, Broome MR. Adult attention deficit hyperactivity symptoms and psychosis: epidemiological evidence from a population survey in England. Psychiatry Res 2015; 229:4956.

58. Levy E, Traicu A, Iyer S, Malla A, Joober R. Psychotic disorders comorbid with attention-deficit hyperactivity disorder: an important knowledge gap. Can J Psychiatry 2015; 60:S48-S52.

59. Becker SP, Leopold DR, Burns GL, Jarrett MA, Langberg JM, Marshall SA, McBurnett K7, Waschbusch DA8, Willcutt EG. The internal, external, and diagnostic validity of sluggish cognitive tempo: a meta-analysis and critical review. J Am Acad Child Adolesc Psychiatry 2016; 55:163-178.

60. Becker SP, Barkley RA. Sluggish cognitive tempo: In Banaschewski T, Coghill D, Zuddas A (editors). Oxford Textbook of Attention Deficit Hyperactivity Disorder. Oxford: Oxford University Press, 2018, 147-153. 